\title{
Modelling of Environmental Risk Management under Information Asymmetry
}

\author{
Petr Šauer, Petr Fiala, and Antonín Dvořák \\ University of Economics, W. Churchilla 4, 13067 Prague 3, Czech Republic \\ \{sauer, pfiala, advorak\} @vse.cz
}

\begin{abstract}
The Environmental risk management is an important component of governmental environmental policies. Alternative mechanisms for achieving cost-effective environmental risk reduction have been discussed in environmental economics. The paper presents a relatively new approach to environmental risk management - a model of negotiation between polluters and authorities under information asymmetry when also economic instruments are applied. A combinatory model that serves computing the first best solution was developed. The CRAB software (CombinatoRial Auction Body Software System) was used for this model. The computed first best solution was compared to the results of small economic laboratory experiments. Students played the role of the subjects in the experiments. The research concluded that under economic pressure in the form of known limitation of financial resources, the experiment results are closer to minimal financial supports. Even in a one-round game, a more cost-effective solution is achieved compared to experiments where such limitation was not introduced.
\end{abstract}

Keywords: environmental risk, management, pollution, combinatorial auctions, environmental subsidy, economic laboratory experiments.

\section{Introduction}

Reducing environmental risks in a cost-effective way is an important issue in environmental economics and policy. Three kinds of environmental policy instruments are able to achieve this solution: tradable pollution rights (permits), environmental charges/taxes and financial supports.

This paper presents a relatively new approach to environmental risk management. It is a negotiation between polluters and authorities (mostly government in practice) where economic instruments of environmental policies in the form of financial support are applied and where there is an information asymmetry between the authority and the polluters. The authority distributes financial resources in a one-round auction. The polluters know their individual abatement costs and try to maximize their surplus, which they can get if they apply for and negotiate higher support from the authority than the minimum they need, so their project is efficient for them. They are also allowed to establish coalitions to achieve goals in environmental risk reduction. After

J. Hřebíček et al. (Eds.): ISESS 2013, IFIP AICT 413, pp. 391 402, 2013.

(C) IFIP International Federation for Information Processing 2013 
negotiating with the coalition partner(s), they apply for financial support to the coalition project(s) together with their individual projects.

The research questions were as follows: (i) to what extent can the negotiated result be close to the computed optimum solution, (ii) what is the role of the financial pressure on the subjects and pay-offs, and (iii) how do the coalition subjects distribute the "extra cake" from getting higher support than the minimum?

Economic laboratory experiments were used as the method to answer the research questions. It is possible to observe increasing use of economic laboratory experiments in research. Supporters of these experiments argue that the experiments can serve well in fundamental research for (pre)testing theoretical hypotheses and continuing to build theories. In applied research, the experiments serve testing various institutional settings that are considered for introduction in policy practice. For the use of economic laboratory experiments for research purposes and its advantages and disadvantages, see for instance [1-7].

The paper is structured as follows: The general model of combinatorial auctions is presented first. Theoretical optimum results for a case with 10 polluters computed with the use of the CRAB software are compared with experimental results, where financial pressure and pay-offs were not introduced. A new series of laboratory experiments where financial pressure and pay-offs are introduced is described and the results are presented in the last part.

\section{Combinatorial Auctions - General Model}

Combinatorial auctions serve as a theoretical framework for the approach presented in the paper. Auctions are important market mechanisms for the allocation of goods and services. Auctions have emerged as a particularly interesting tool for negotiations. An auction provides a mechanism for negotiation between buyers and sellers. Combinatorial auctions [8-9] are those auctions in which bidders can place bids on combinations of items, so-called bundles. The advantage of combinatorial auctions is that the bidder can express his preferences more fully. This is particularly important when the items are complements. The auction designer also derives value from combinatorial auctions. Allowing bidders to express preferences more fully often leads to improved economic efficiency and greater auction revenues. It is possible to formulate single-sided combinatorial auctions, forward auctions and reverse auctions. In forward auctions, a single seller sells resources to multiple buyers. In reverse auctions, a single buyer attempts to source resources from multiple suppliers, as is common in procurement.

The problem, called the winner determination problem, has received considerable attention in the literature. The problem is formulated as follows: Given a set of bids in a combinatorial auction, find an allocation of items to bidders that maximize the seller's revenue. Many important ideas are introduced, such as the mathematical programming formulation of the winner determination problem, the connection between the winner determination problem and the set packing problem, as well as the issue of complexity.

Many types of combinatorial auctions can be formulated as mathematical programming problems. Among the different types of combinatorial auctions, we present the reverse auction of indivisible items with one buyer and several sellers. This type 
of auction is important for the supplier selection problem. This type of auctioning serves as the theoretical basis for our case, where the polluters sell their contributions to environmental risk reduction when investing in pollution reduction projects.

Let us suppose that $m$ potential sellers $S 1, S 2, \ldots$, Sm offer a set $R$ of $r$ items, $j=1$, $2, \ldots, r$, to one buyer B (see Fig. 1).

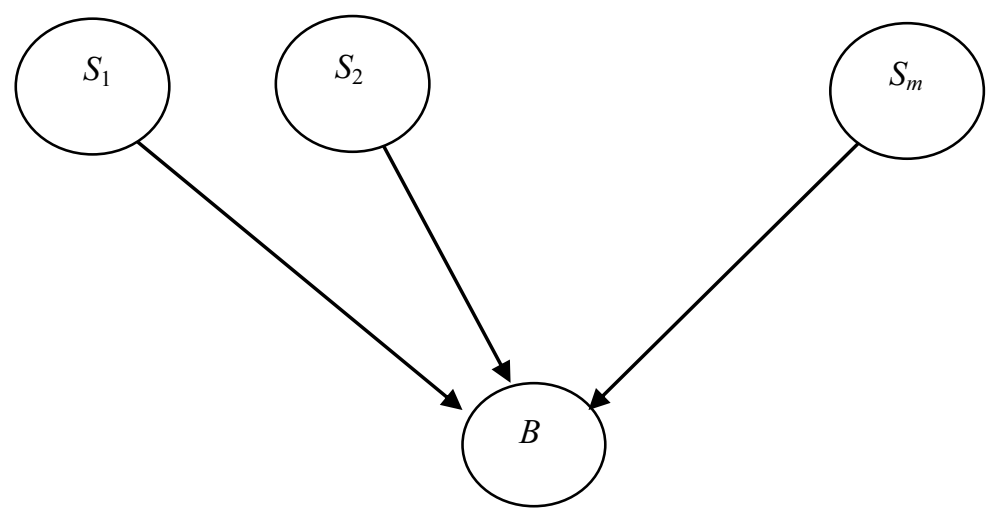

Fig. 1. Reverse auction

A bid $b_{h}$ made by the seller $S_{h}, h=1,2, \ldots, m$, is defined as

$$
b_{h}=\left\{C, c_{h}(C)\right\} \text {, }
$$

where

$\mathrm{C} \subseteq \mathrm{R}$, is a combination of items,

$\operatorname{ch}(\mathrm{C})$, is the offered price by seller Sh for the combination of items C.

The objective is to minimize the buyer's cost given the bids made by sellers. Constraints establish that the procurement provides at least a set of all items.

Bivalent variables are introduced for model formulation:

$y_{h}(C)$ is a bivalent variable specifying whether the combination $C$ is bought from the seller $S_{h}\left(y_{h}(C)=1\right)$.

The reverse combinatorial auction can be formulated as follows

$$
\sum_{h=1}^{m} \sum_{C \subseteq R} c_{h}(C) y_{h}(C) \rightarrow \min
$$

subject to

$$
\begin{gathered}
\sum_{h=1}^{m} \sum_{C \subseteq R} y_{h}(C) \geq 1, \quad \forall j \in R, \\
y_{h}(C) \in\{0,1\}, \forall C \subseteq R, \quad \forall h, h=1,2, \ldots, m .
\end{gathered}
$$


The objective function expresses the cost. The constraints ensure that the procurement provides at least a set of all items.

The CRAB (CombinatoRial Auction Body) software system was proposed [10]. The CRAB is a non-commercial software system for generating, solving, and testing of combinatorial auction problems. The system solves problems using Balas' method or the primal-dual algorithm.

\section{Base Experimental Case}

An ideal model territory was created for the laboratory experiment. There were 10 polluters in 5 groups specified as A, B, C, D and E. This group also shows where it makes sense (from the economic point of view) to think about coalition projects (see Fig. 2).

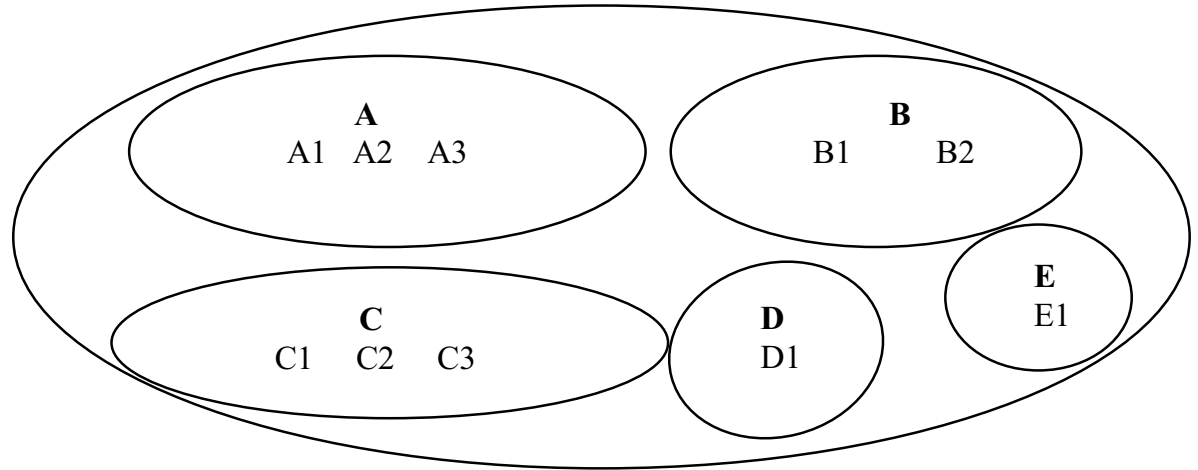

Fig. 2. Polluters in the region

Information about 10 individual projects (A1, A2, A3; B1, B2; C1, C2, C3; D; E1) and for 9 coalition projects (A1-A2, A1-A3, A2-A3, A1-A2-A3; B1-B2; C1-C2, C1$\mathrm{C} 3, \mathrm{C} 2-\mathrm{C} 3, \mathrm{C} 1-\mathrm{C} 2-\mathrm{C} 3)$ was prepared. The environmental effects were expressed as emission reduction (as an easy-to-understand indicator), but environmental risk reduction could also be applied. The following indicators were prepared for each of the projects:

Pollution reduction $\mathrm{dEi}, \mathrm{i}=1,2, \ldots, 19$,

Minimum financial support Pmini, $\mathrm{i}=1,2, \ldots, 19$, needed from an external source, so the projects are economically efficient for the subject. The minimum financial support was based on the idea of so-called net abatement costs [11].

A table with all the experimental data can be found in [12]. The subjects playing the role of the managers were asked to reduce the pollution by a given amount for each of the groups. They could apply for support for individual projects and/or negotiate within the group for support for coalition projects. Students of the University of Economics played the role of the polluters. Teachers - authors of the paper - played the role of the authority. A cost-effective solution was computed with the CRAB software. The results of 8 experiments (E1 ... E8) were compared to this first best solution. 
The main goal of these economic laboratory experiments was to test whether and to what extent it is possible to establish coalitions that will solve the problem of pollution reduction with the lowest costs. The experiment was already complex enough, so it would be difficult to stimulate the subjects to reduce their bids. It would be possible via introducing multi-round negotiations. For more details about this experiment, see [12].

Table 1. Comparing computed and experimental results

\begin{tabular}{|l|l|l|l|l|l|l|l|c|}
\hline Computed optimum solution & E1 & E2 & E3 & E4 & E5 & E6 & E7 & E8 \\
\hline Experiment no. & 520 & 348 & 470 & 417 & 521 & 370 & 500 & 510 \\
\hline Negotiated financial support & 340 & 280 & 270 & 310 & 315 & 270 & 300 & 290 \\
\hline Minimum support &
\end{tabular}

Most of the experiments achieved close to the optimum (first best) solution in terms of the structure of selected projects (i.e. the "right" coalitions were found). It can be seen in Table 1 that without the application of multi-round negotiations or/and a financial pressure on the subjects, the negotiated financial support is very high.

\section{$4 \quad$ Partially Detailed Experiments - Design and Results}

Two experiments were prepared. The case for them was derived from the base experiment mentioned in Section 3, including the data where also the first best solution was computed. The first experiment was designed for groups of two subjects. The second experiment was elaborated for groups of three subjects.

\subsection{Experiment Design}

\section{Experiment Design for Groups of Two Subjects (A and B)}

Pollution reduction by individual projects: $\mathrm{dPA}, \mathrm{dPB}$

Pollution reduction by a joint project: $\mathrm{dPAB}=\mathrm{dPA}+\mathrm{dPB}$

Costs of individual projects: $\mathrm{CA}, \mathrm{CB}$

Costs of joint (coalition) project: $\mathrm{CAB}$

\section{Experiment Design for Groups of Three Subjects (A, B and C)}

Pollution reduction by individual projects: $\mathrm{dPA}, \mathrm{dPB}, \mathrm{dPC}$

Pollution reduction by joint projects: $\mathrm{dPAB}=\mathrm{dPA}+\mathrm{dPB} ; \mathrm{dPAC}=\mathrm{dPA}+\mathrm{dPC}$; $\mathrm{dPBC}=\mathrm{dPB}+\mathrm{dPC} ; \mathrm{dPABC}=\mathrm{dPA}+\mathrm{dPB}+\mathrm{dPC}$

Costs of individual projects: $\mathrm{CA}, \mathrm{CB}, \mathrm{CC}$

Costs of joint (coalition) projects: $\mathrm{CAB}, \mathrm{CAC}, \mathrm{CBC}, \mathrm{CABC}$

Sixteen students of the University of Economics, Prague ( 8 in international trade major and 8 in theory of decision making major) and sixteen students of the College of Polytechnics Jihlava (management of tourism major) were subjects in the experiments. They played the roles of managers applying for the financial support from the authority. The role of the authority was played by the teacher (the same person in all the experiments). 
The subjects in the role of managers were given the following materials (see attachment for more details):

- The situation (case) description

- Training (non-confidential) data for better understanding the experiment

- Confidential data for the experiment(s)

- Application form for financial support from the authority.

The subject playing the role of the authority had the same materials as the students plus a description of details of the experimental process to keep the same conditions in all the repetitions of the experiments.

The subject playing the role of the authority distributed the materials, made a picture of the situation on the blackboard and explained the case, demonstrated the managers' decision making process on the training data, and collected the filled-in application forms for financial support from the subjects at the end of the experiments. He also informed the subjects that there is one round of application possible, that the financial resources for financial support are limited (i.e., not all applications can be supported) and that the subject will be financially rewarded after the experiments (CZK 30 for showing up + part of the surplus they will negotiate in the experiment).

\subsection{Experiment Results for Groups of Two Subjects (Table 2)}

\section{Solution for Individual Groups}

The first-best solution for groups of two subjects (A, B) is to establish the coalition $\mathrm{AB}$ with a total pollution reduction of 70 units and a minimum support of 50 monetary units. All these groups established coalitions with minimum requested support of 72.5 monetary units on average in the University of Economics experiments (71.4 monetary units in the Polytechnics Jihlava experiments). In the base experiment (see Section 3) without pressure, the requested support was 85 monetary units on average.

\section{Solution for the Whole Region}

If we presume pollution reduction in the whole region by $60 \%$, the total pollution reduction would be 336 units $(0.6 * 8 * 70=336)$. By solving the combinatorial reverse auction problem (see Section 2), we get a solution of selected coalitions: 1AB, 4A, $5 \mathrm{AB}, 6 \mathrm{AB}, 7 \mathrm{AB}, 8 \mathrm{~A}$; the minimum support would be 323.6 monetary units in the University of Economics experiments (1A, 4AB, 5AB, 6AB, 7A, 8AB); the minimum support would be 316 monetary units in the Polytechnics Jihlava experiments). The solutions are not trivial; they are combinations of one- and two-element coalitions. 
Table 2. Results of the experiment for groups of two subjects

\begin{tabular}{|c|c|c|c|c|c|c|c|}
\hline \multirow{2}{*}{ Project } & \multirow{2}{*}{$\begin{array}{c}\text { Pollution } \\
\text { reduction }\end{array}$} & & \multicolumn{2}{|c|}{ Univ. of Economics, Prague } & \multicolumn{3}{c|}{ Polytechnics Jihlava } \\
\cline { 3 - 8 } & & $\begin{array}{c}\text { Required } \\
\text { support }\end{array}$ & Surplus A & Surplus B & $\begin{array}{c}\text { Required } \\
\text { support }\end{array}$ & Surplus A & Surplus B \\
\hline 1A & 30 & 30 & 10 & - & 25 & 5 & - \\
\hline 1B & 40 & 78 & - & 18 & 70 & - & 10 \\
\hline 1AB & 70 & $70^{*}$ & 9 & 11 & $70^{*}$ & 10 & 10 \\
\hline 2A & 30 & 35 & 15 & - & 50 & 30 & - \\
\hline 2B & 40 & 95 & - & 35 & 90 & - & 30 \\
\hline 2AB & 70 & $80^{*}$ & 10 & 20 & $80^{*}$ & 15 & 15 \\
\hline 3A & 30 & 30 & 10 & - & 30 & 10 & - \\
\hline 3B & 40 & 70 & - & 10 & 75 & - & 15 \\
\hline 3AB & 70 & $75^{*}$ & 15 & 10 & $75^{*}$ & 15 & 10 \\
\hline 4A & 30 & 27 & 7 & - & 32 & 12 & - \\
\hline 4B & 40 & 70 & - & 10 & 75 & - & 15 \\
\hline 4AB & 70 & $80^{*}$ & 10 & 20 & $72^{*}$ & 10 & 12 \\
\hline 5A & 30 & 23.5 & 3.5 & - & 30 & 10 & - \\
\hline 5B & 40 & 80 & - & 20 & 68 & - & 8 \\
\hline 5AB & 70 & $70^{*}$ & 8 & 12 & $64^{*}$ & 6 & 8 \\
\hline 6A & 30 & 30 & 10 & - & 30 & 10 & - \\
\hline 6B & 40 & 80 & - & 20 & 75 & - & 15 \\
\hline 6AB & 70 & $70^{*}$ & 10 & 10 & $70^{*}$ & 5 & 15 \\
\hline 7A & 30 & 35 & 15 & - & 25 & 5 & - \\
\hline 7B & 40 & 65 & - & 5 & 90 & - & 30 \\
\hline 7AB & 70 & $65^{*}$ & 7 & 8 & $80^{*}$ & 10 & 20 \\
\hline $\mathbf{8 A}$ & 30 & 21.6 & 1.6 & - & 30 & 10 & - \\
\hline $\mathbf{8 B}$ & 40 & 70 & - & 10 & 70 & - & 10 \\
\hline $\mathbf{8 A B}$ & 70 & $70^{*}$ & 10 & 10 & $60^{*}$ & 4 & 6 \\
\hline
\end{tabular}

\section{Distribution of Surplus}

The total surplus in the experiments under pressure is lower than in the experiments without pressure. The distribution of surplus in negotiations between the subjects $\mathrm{A}$ and B is $9.9: 12.6$ average in the University of Economics experiments $(9.4: 12$ in the Polytechnics Jihlava experiments).

\subsection{Experiment Results for Groups of Three Subjects (Table 3)}

\section{Solution for Individual Groups}

The first-best solution for groups of three subjects $(\mathrm{A}, \mathrm{B}, \mathrm{C})$ is to establish the big coalition $\mathrm{ABC}$ (total pollution reduction of 230 units) with a minimum support of 60 monetary units.

Six groups of three subjects (1-6) established the big coalition with a minimum requested support of 94 on average. Group no. 7 proposed the best solution by establishing the coalition $\mathrm{AB}$ (requested support 45) and $\mathrm{C}$ (requested support 50), totalling 95 monetary units. The requested support for the big coalition was 99 monetary units. 
Table 3. Results of the experiment for groups of three subjects

\begin{tabular}{|c|c|c|c|c|c|}
\hline Project & Pollution Reduction & Required support & Surplus A & Surplus B & Surplus C \\
\hline 1A & 90 & 35 & 5 & - & - \\
\hline 1B & 40 & 65 & - & 35 & - \\
\hline $1 \mathrm{C}$ & 100 & 75 & - & - & 25 \\
\hline 1AB & 130 & 50 & 7 & 8 & - \\
\hline 1AC & 190 & 100 & 10 & - & 20 \\
\hline $1 \mathrm{BC}$ & 140 & 90 & - & 15 & 15 \\
\hline $\mathbf{1 A B C}$ & 230 & 90 & 10 & 10 & 10 \\
\hline $2 \mathbf{A}$ & 90 & 41 & 11 & - & - \\
\hline 2B & 40 & 45 & - & 15 & - \\
\hline $2 \mathrm{C}$ & 100 & 66 & - & - & 16 \\
\hline $2 \mathrm{AB}$ & 130 & 55 & 10 & 10 & - \\
\hline 2AC & 190 & 88 & 8 & - & 10 \\
\hline 2BC & 140 & 78 & - & 9 & 9 \\
\hline $2 \mathrm{ABC}$ & 230 & 84 & 8 & 7 & 9 \\
\hline $\mathbf{3 A}$ & 90 & 50 & 20 & - & - \\
\hline 3B & 40 & 40 & - & 10 & - \\
\hline $3 \mathrm{C}$ & 100 & 85 & - & - & 35 \\
\hline 3AB & 130 & 55 & 15 & 5 & - \\
\hline 3AC & 190 & 100 & 10 & - & 20 \\
\hline 3BC & 140 & 80 & - & 5 & 15 \\
\hline 3ABC & 230 & 90 & 5 & 5 & 20 \\
\hline $\mathbf{4 A}$ & 90 & 55 & 25 & - & - \\
\hline 4B & 40 & 40 & - & 10 & - \\
\hline $4 \mathrm{C}$ & 100 & 60 & - & - & 10 \\
\hline 4AB & 130 & 50 & 10 & 5 & - \\
\hline 4AC & 190 & 85 & 5 & - & 10 \\
\hline $4 \mathrm{BC}$ & 140 & 70 & - & 5 & 5 \\
\hline 4ABC & 230 & 80 & 5 & 5 & 10 \\
\hline $5 \mathrm{~A}$ & 90 & 40 & 10 & - & - \\
\hline 5B & 40 & 35 & - & 5 & - \\
\hline $5 \mathrm{C}$ & 100 & 75 & - & - & 25 \\
\hline 5AB & 130 & 45 & 5 & 5 & - \\
\hline $5 \mathrm{ACC}$ & 190 & 90 & 10 & - & 10 \\
\hline $5 \mathrm{BC}$ & 140 & 90 & - & 15 & 15 \\
\hline $5 \mathrm{ABC}$ & 230 & 100 & 14 & 13 & 13 \\
\hline $6 \mathrm{~A}$ & 90 & 40 & 10 & - & - \\
\hline 6B & 40 & 45 & - & 15 & - \\
\hline $6 \mathrm{C}$ & 100 & 60 & - & - & 10 \\
\hline 6AB & 130 & 55 & 10 & 10 & - \\
\hline 6AC & 190 & 100 & 15 & - & 15 \\
\hline $6 \mathrm{BC}$ & 140 & 90 & - & 15 & 15 \\
\hline 6ABC & 230 & 120 & 20 & 20 & 20 \\
\hline $7 \mathrm{~A}$ & 90 & 40 & 10 & - & - \\
\hline $7 B$ & 40 & 40 & - & 10 & - \\
\hline $7 \mathrm{C}$ & 100 & 50 & - & - & 0 \\
\hline 7AB & 130 & 45 & 3 & 7 & - \\
\hline 7AC & 190 & 85 & 8 & - & 7 \\
\hline $7 \mathrm{BC}$ & 140 & 70 & - & 4 & 6 \\
\hline $7 \mathrm{ABC}$ & 230 & 99 & 13 & 13 & 13 \\
\hline
\end{tabular}

In the base experiment (see Section 3) without pressure, the requested support was 133.125 on average, which is almost $50 \%$ more. 


\section{Solution for the Whole Region}

If we presume pollution reduction in the whole region by $60 \%$, the total pollution reduction would be 966 units $(0.6 * 7 * 230=966)$. By solving the combinatorial reverse auction problem (see Section 2), we get a solution of selected coalitions: $1 \mathrm{AB}$, $2 \mathrm{ABC}, 4 \mathrm{ABC}, 5 \mathrm{AB}, 6 \mathrm{AB}, 7 \mathrm{AB}$; the minimum support would be 359 monetary units. The solution is not trivial; it is a combination of two- and three-element coalitions.

\section{Distribution of Surplus}

The total surplus in the experiments under pressure with three subjects is lower than in the experiments without pressure. The distribution of surplus in negotiations among the subjects A, B and C is $10.7: 10.4$ : 13.6 on average."

\section{$5 \quad$ Concluding Remarks}

Modelling of environmental risk management under information asymmetry seems to be a very promising area of research. The aim of this paper was to contribute to a theoretical framework and compare the computed theoretical first-best solution with experimental results. Models of combinatorial auctions were selected as the theoretical framework. A base experimental case and partially detailed experiments were created and used for testing the basic research questions in the paper, which were as follows: (i) to what extent can the negotiated results be close to the computed optimal solution, (ii) what is the role of financial pressure on the subjects and pay-offs, and (iii) how do the coalition subjects distribute the "extra cake" from getting higher support than the minimum?

The experiments showed that the experimental results were close to theoretical results mainly in the structure of the solution, i.e., the structure of selected coalitions to the structure of the first best solution. The required supports are significantly closer to the theoretical minimum supports in the experiments under financial pressure than in the situations without the pressure, i.e., in the situations where all the subjects get the supports and there is no pay-off for the subjects in the experiments. The negotiated distributions of the surplus among the subjects are, on average, fairly balanced. Small differences are caused by the position of the subject in establishing coalitions. An interesting observation is the finding that the results are very similar for groups of students (experimental subjects) from different universities.

The results in the paper inspire us to continue experiments for a richer structure of coalitions with multi-round negotiations under pressure and with the introduction of multi-criteria evaluation of environmental and other effects performed by the authorities. These more general cases promise to bring new interesting findings. The EU Operational Programme Environment (OPE) support for water management infrastructure and the reduction of flood risks is a typical field of application for establishing joint (coalition) projects supported from public funds. We believe that it also makes sense to develop one-round models. This procedure is typical for various support programmes, such as the grants provided from the OPE for reducing industrial pollution and environmental risks. 
Acknowledgement. The paper was developed with the support of the Czech Science Foundation, grant no.13-07036S "Modelling of Negotiations in Environmental Policy under Information Asymmetry".

\section{References}

1. Davis, D.D., Holt, C.A.: Experimental Economics. Princeton University Press, Princeton (1993)

2. Smith, V.L.: Experimental Economics: Induced Value Theory. The American Economic Review 66(2), 274-279 (1976)

3. Walker, J.: Economic Instruction: Experimental Economics in the Classroom. Journal of Economic Education 18(1), 51-56 (1987)

4. Roth, A.E.: Introduction to Experimental Economics. In: Kagel, J.H., Roth, A.E. (eds.) The Handbook of Experimental Economics, pp. 3-109. Princeton University Press, New Jersey (1995)

5. Sauer, P., Dvorak, A., Lisa, A., Fiala, P.: A Procedure for Negotiating Pollution Reduction under Information Asymmetry. Environmental and Resource Economics 24, 103-119 (2003)

6. Levitt, S.D., List, J.A.: What Do Laboratory Experiments Measuring Social Preferences Reveal about the Real World? The Journal of Economic Perspectives 21(2), 153-174 (2007)

7. Falk, A., Heckman, J.: Lab Experiments are a Major Source of Knowledge in the Social Sciences. CESifo Working Paper Series, No. 2894. Available at SSRN on-line (2009), http: / /ssrn. com/abstract $=1536400$ (assessed March 20, 2013)

8. Cramton, P., Shoham, Y., Steinberg, R. (eds.): Combinatorial Auctions. MIT Press, Cambridge (2006)

9. de Vries, S., Vohra, R.V.: Combinatorial auctions: A survey. INFORMS Journal of Computing 15(1), 284-309 (2003)

10. Fiala, P., Kalčevová, J., Vraný, J.: CRAB—CombinatoRial Auction Body Software System. Journal of Software Engineering and Applications 3(7), 718-722 (2010)

11. Šauer, P., Dvořák, A., Fiala, P.: Negotiation between authority and polluters: A model for the support of decision-making in ecological policy (in Czech). Politická Ekonomie, XLVI/6, 772-787 (1998)

12. Fiala, P., Šauer, P.: Application of Combinatorial Auctions on Allocation of Public Financial Support in the Area of Environmental Protection: Economic Laboratory Experiment (in Czech). Politická Ekonomie, 59(3), 379-392 (2011) 


\section{Annex - Text Distributed to the Subjects (Polluter a as an Example; Case of the Groups of Three Subjects)}

\section{Case Situation}

In the region in which your Firm [ A ] is located, there are several sources of environmental pollution. It is important to reduce this pollution due to fulfilment of an international agreement in the field of environmental risk reduction. Each of the polluters has four potential projects for reducing the pollution in the region. The individual project is one of the options. Joint (coalition) projects with the other firms [ B, C ] is the other option. Each of the projects (i.e., individual or coalition ones) offers some pollution reduction $(\mathrm{dP})$, requires some costs $(\mathrm{C})$ and needs some minimum external financial support (Smin). The firms and/or their coalitions apply for this financial support at the authority. The application procedure has one round. In the application forms, you are supposed to fill in:

a) Pollution reduction offered (see $\mathrm{dP}$ in the Confidential data ...) and

b) Required amount of financial support; its amount is based on your negotiation strategy; you must not request less than the shown minimum amount (Smin in the Confidential data ...).

The financial resources for the support are limited. The support will be distributed to the most efficient projects, i.e., not all projects can be supported. If you succeed in getting higher support than the minimum you need (Smin), you get a surplus. The whole surplus belongs to you in the case your individual project is supported. In case a coalition project is supported, you share the surplus with the other firms in the coalition. The shares in the surplus are negotiated with the other firms before the application is submitted.

You will be rewarded for your participation in the experiment. The remuneration will consist of a show-up fee of CZK 30 and the amount derived from the amount of surplus you get.

Training data (non-confidential data for better understanding the experiment by the subjects; case of the group of two subjects):

\begin{tabular}{|l|c|c|c|}
\hline Data for polluter X & $\begin{array}{c}\text { Pollution reduction } \\
(\mathrm{dP})\end{array}$ & $\begin{array}{l}\text { Cost of the } \\
\text { project (C) }\end{array}$ & $\begin{array}{l}\text { Minimum finan- } \\
\text { cial support } \\
\text { (Smin) }\end{array}$ \\
\hline $\begin{array}{l}\text { Individual solution } \\
\text { (project) }\end{array}$ & 20 & 50 & 25 \\
\hline $\begin{array}{l}\text { Joint solution (pro- } \\
\text { ject A+B) }\end{array}$ & 40 & 80 & 40 \\
\hline
\end{tabular}




\begin{tabular}{|l|c|c|c|}
\hline Data for polluter Y & $\begin{array}{l}\text { Pollution reduction } \\
(\mathrm{dP})\end{array}$ & $\begin{array}{l}\text { Cost of the } \\
\text { project (C) }\end{array}$ & $\begin{array}{l}\text { Minimum finan- } \\
\text { cial support } \\
\text { (Smin) }\end{array}$ \\
\hline $\begin{array}{l}\text { Individual solution } \\
\text { (project) }\end{array}$ & 20 & 60 & 30 \\
\hline $\begin{array}{l}\text { Joint solution (pro- } \\
\text { ject A+B) }\end{array}$ & 40 & 80 & 40 \\
\hline
\end{tabular}

Confidential data for the subject playing the role of the polluter [ A ] in the experiment with three subjects for whom it might be efficient to establish a coalition:

\begin{tabular}{|l|l|l|l|}
\hline & $\begin{array}{l}\text { Pollution reduction } \\
(\mathrm{dP})\end{array}$ & $\begin{array}{l}\text { Cost of the } \\
\text { project } \\
(\mathrm{C})\end{array}$ & $\begin{array}{l}\text { Minimum finan- } \\
\text { cial support } \\
\text { (Smin) }\end{array}$ \\
\hline $\begin{array}{l}\text { Individual solution } \\
\text { (project) }\end{array}$ & \multicolumn{3}{|l}{} \\
\hline A & 90 & 60 & 30 \\
\hline Joint solutions & \multicolumn{3}{|l}{} \\
\hline A+B & 130 & 70 & 35 \\
\hline A+C & 190 & 140 & 70 \\
\hline A+B+C & 230 & 120 & 60 \\
\hline
\end{tabular}

Application form for financial support from government (case of the group of three subjects):

Polluter [ A ]

Experiment no.:

Date:

Subject (student):

\begin{tabular}{|l|l|l|c|}
\hline & $\begin{array}{l}\text { Pollution reduction } \\
\text { offered (dP) from } \\
\text { Confidential } \\
\text { data.... }\end{array}$ & $\begin{array}{l}\text { Financial support } \\
\text { required } \\
\text { Your decision }\end{array}$ & $\begin{array}{l}\text { Your share in } \\
\text { the surplus1) }\end{array}$ \\
\hline $\begin{array}{l}\text { Individual solution } \\
\text { (project) }\end{array}$ & $\mathrm{X}$ & $\mathrm{x}$ & $\mathrm{X}$ \\
\hline $\begin{array}{l}\text { Joint solutions } \\
\text { (projects) with } \\
\text { your participation }\end{array}$ & & & \\
\hline $\mathrm{A}+\mathrm{B}$ & & & \\
\hline $\mathrm{A}+\mathrm{C}$ & & & \\
\hline $\mathrm{A}+\mathrm{B}+\mathrm{C}$ & & & \\
\hline
\end{tabular}

In the case of joint projects, the sum of the individual firms' shares in the surplus has to be equal to the whole surplus of the joint project. 